\title{
OSTEOPETROSIS IN SUCCESSIVE GENERATIONS
}

\author{
BY \\ JOHN THOMSON, M.D., D.P.H., D.C.H. \\ Paediatrician, Royal Blind Asylum, Edinburgh \\ (From the Department of Child Life and Health, University of Edinburgh)
}

Records of families in which osteopetrosis has appeared in successive generations are rare. The occurrence of the condition in mother and son is recorded in this paper.

\section{Case Histories}

Case 1. A full-term male child, weighing $6 \frac{1}{2} \mathrm{lb}$., the product of a second pregnancy, was born on Aug. 3, 1945. The parents were unrelated. When three months old the child was thought to be blind, and two months later on $x$-ray examination a diagnosis of osteopetrosis was made. Mental retardation was noted at ten months. At two years two months he was admitted to the Royal Blind School; he was a well built and well nourished child (fig. 1).

When two and a half years old he weighed $28 \mathrm{lb}$., was 33 in. tall, had a crown-rump measurement of $19 \frac{1}{2}$ in., and an arm span of 31 in. The intermeatal measurement was $12 \frac{1}{2}$ in., the occipito-frontal circumference $19 \frac{3}{4}$ in. The thoracic circumference at the nipple level was 19 in. The head showed slight frontal and more marked parietal bossing. The general outline suggested a degree of hydrocephalus. The pupils did not react to light and there was bilateral optic atrophy. Nasal obstruction and mouth-breathing were present. Dental eruption had been normal and the teeth appeared in good condition, though the lower lateral incisors and lower right second molar were missing. No enlargement of liver, spleen, or lymph glands was present.

Blood examination showed erythrocytes 4,925,000 per c.mm. of blood; haemoglobin (Sahli) 95 per cent.; white blood corpuscles 12,500 per c.mm.; polymorphs: neutrophils 18.5 per cent.; cosinophils 1.5 per cent.; basket cells 4 per cent.; large lymphocytes 12.5 per cent.; small lymphocytes 57 per cent.; smear cells 4.5 per cent.; monocytes 2 per cent. No nucleated red cells or primitive white cells were seen.

Blood chemistry investigation gave a blood urea nitrogen of $17 \mathrm{mg}$. per $100 \mathrm{c.cm}$. of blood; serum calcium 10.2 to $11.8 \mathrm{mg}$; inorganic phosphorus 4. 1 to $4.4 \mathrm{mg}$; phosphatase 8 units (King).

Radiographs of the skull and limbs showed the typical picture of osteopetrosis. In the skull (fig. 2) the anterior fontanelle was not completely closed and the suture lines were obvious. The increased density of the bones at the base of the skull was marked, as was the thickening of the posterior clinoid processes. The symmetrical nature of the condition was well demonstrated in radiographs of the limbs (figs. 3, 4, and 5). Clubbing of the lower end of the femur was typical. Comparison of figs. 4 and 5 shows that while there have been remissions in the sclerotic process at the distal end of the femur, there has been no accompanying remission in the clubbing. The humeri showed marked clubbing in the proximal thirds of the shafts.

When two years five months old the child showed evidence of pain and discomfort in the left forearm. Clinical examination, which disclosed the presence of some swelling, was resented. X-ray examination confirmed the diagnosis of a fracture of the left radius. No cause could be assigned in explanation of the injury. The fracture was situated in an area of sclerosis and showed no displacement. The arm was splinted and in twenty-four hours the child was using it freely. Callus formation was satisfactory (fig. 6). Six weeks later similar behaviour led to the discovery of a fracture of the right fibula. There was no displacement, and thirty-six hours after being $x$-rayed and having the leg splinted the child was observed to walk voluntarily. Callus formation was satisfactory. At this stage, the child was considered to be ineducable and was discharged from the Royal Blind School when two years eight months old.

Case 2. The mother of case 1 was the fifth child of healthy unrelated parents. She was born on Jan. 4, 1920. The condition was not suspected in her case until the diagnosis had been made in the case of her son. Her features and the shape of her head bore a striking resemblance to that of her child. There was no mental defect. Visual acuity was R. 6/6; L. 6/6. No enlargement of liver, spleen, or lymph glands was detected.

X-ray examination showed marked sclerosis of the basal skull bones with clubbed posterior clinoid processes. The suture lines were obvious (fig. 7). The humeri showed increased thickening of the proximal half of the shaft. The sclerotic areas were not sharply demarcated, but shaded off irregularly into areas of more normal bone (fig. 8). A radiograph of the pelvis was typical and disclosed that, as in case 1 , there had been periods of remission in the sclerosing process (Fig. 9). There was no history of fractures. 
No opportunity for further examination of this case was permitted.

Family history. The family relationships are shown in fig. 10.

No evidence of osteopetrosis has been found on $x$-ray examination of the parents of case 2, her husband, or the sibling of case 1 . Among the siblings of case 2, the brother, born in 1915, had a shown remission (compare figs. 4 and 5). The converse is also true, that sclerosis may be present without manifestations of clubbing. Pirie (1930) states that while clubbing is usually symmetrical it is not necessarily so.

The diploic structure of membranous bone is absent (fig. 2). It would appear that stimulus to growth of brain continues though the capacity of

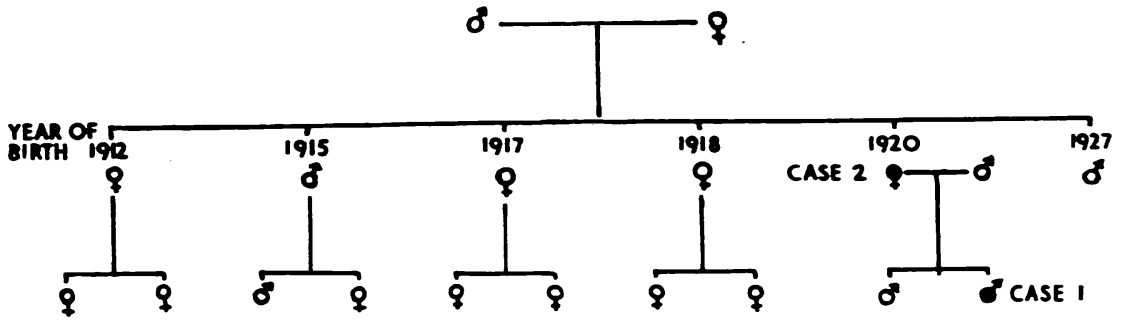

FIG. 10.-Family Relationships.

broken leg while on war service. A radiograph of his leg at that time did not disclose any pathological factor. No further investigation of any member of the family has been permitted. . It is stated that all the offspring of the siblings of case 2 are healthy. The sister, born in 1918, is said to bear a rather striking resemblance in stature and feature to case 2. No investigation of the family of the husband of case 2 has been possible.

\section{Discriscion}

Though it is forty-four years since AlbersSchönberg drew attention to this condition, the cause has not been discovered. Its occurrence has been recorded in Negroes and Asiatics as well as in the white races. Both sexes may be affected.

The condition has been diagnosed while the child was in utero (Pirie, 1930; Clifton et al., 1938; Jenkinson et al., 1943) and it has been diagnosed in late adult life (McPeak, 1936; Pagenstecker, 1935).

Studies of the pathology have established that there is a fault in osteogenesis, followed by a lack of osteoclastic activity. Osteoblasts are decreased in number and osteoclasts may be absent. The resultant picture is one of failure to resorb calcified cartilaginous matrix and remodel the primitive trabeculae. Both membranes and cartilaginous bones are involved in the distribution, which is symmetrical. The bone, though dense, is brittle and fractures easily; the term 'chalky bones' has been used to describe this. The fracture is situated in an area of sclerosed bone and is transverse. It heals without deformity (fig. 6). Dupont (1930) has suggested that the fracture occurs at an area of rarefaction interposed in the sclerosed bone. Unaffected portions of the skeleton may show osteoporosis. Abnormal modelling of bone is manifest in the form of clubbing. This is seen most readily in the posterior clinoid processes, the distal end of the femur, and the proximal end of the humerus. The clubbing is not related to sclerosis since it may persist when the sclerosing process has the skull does not keep pace with it. Some increased intracranial tension must result. The various foramina leading out of the skull are narrowed by the excessive deposit of bone. In the case of the optic foramen this has been demonstrated radiologically by Vidgoff and Bracher (1940) and Clifton et al. (1938) and at autopsy by Lorey and Reye (1923), Krause and Walter (1925), and Alter et al. (1931). It is probable that the narrowing of the optic foramina causes some obstruction to the venous return from the eyes so leading to papilloedema and subsequent optic atrophy. A similar mechanism is suggested by Higinbotham and Alexander (1941) to explain the occurrence of hydrocephalus. Narrowing of the facial nerve canal may produce deafness. Gradual replacement of the marrow space by bone has been usually accepted in explanation of the blood dyscrasia with accompanying hepato-splenomegaly which is characteristic of the so-called malignant type. More recently, it has been suggested that in cases showing blood dyscrasia the primary defect is in the mesenchyme, which is the precursor of both osteoblastic and marrow tissues.

Imperfect or delayed dentition is said to be common. This is not so in either of the cases now recorded; and Vidgoff and Bracher (1940) report the presence of two teeth at birth.

The blood picture, when abnormal, is that of progressive anaemia accompanied by hepatosplepomegaly. Blood platelets remain normal in number, and bleeding, clotting, and fragility tests are unaffected. Studies of blood calcium and phosphorus have shown that there is seldom a departure from normal figures (case 1).

The idea that parathyroid dysfunction may play a part in the etiology of osteopetrosis should not be lightly discarded. While investigating the response of rats to daily injections of parathyroid hormone, Pugsley (1932) found there was first an increase in calcium excretion for four days. This was followed by normal or subnormal excretion of calcium, 

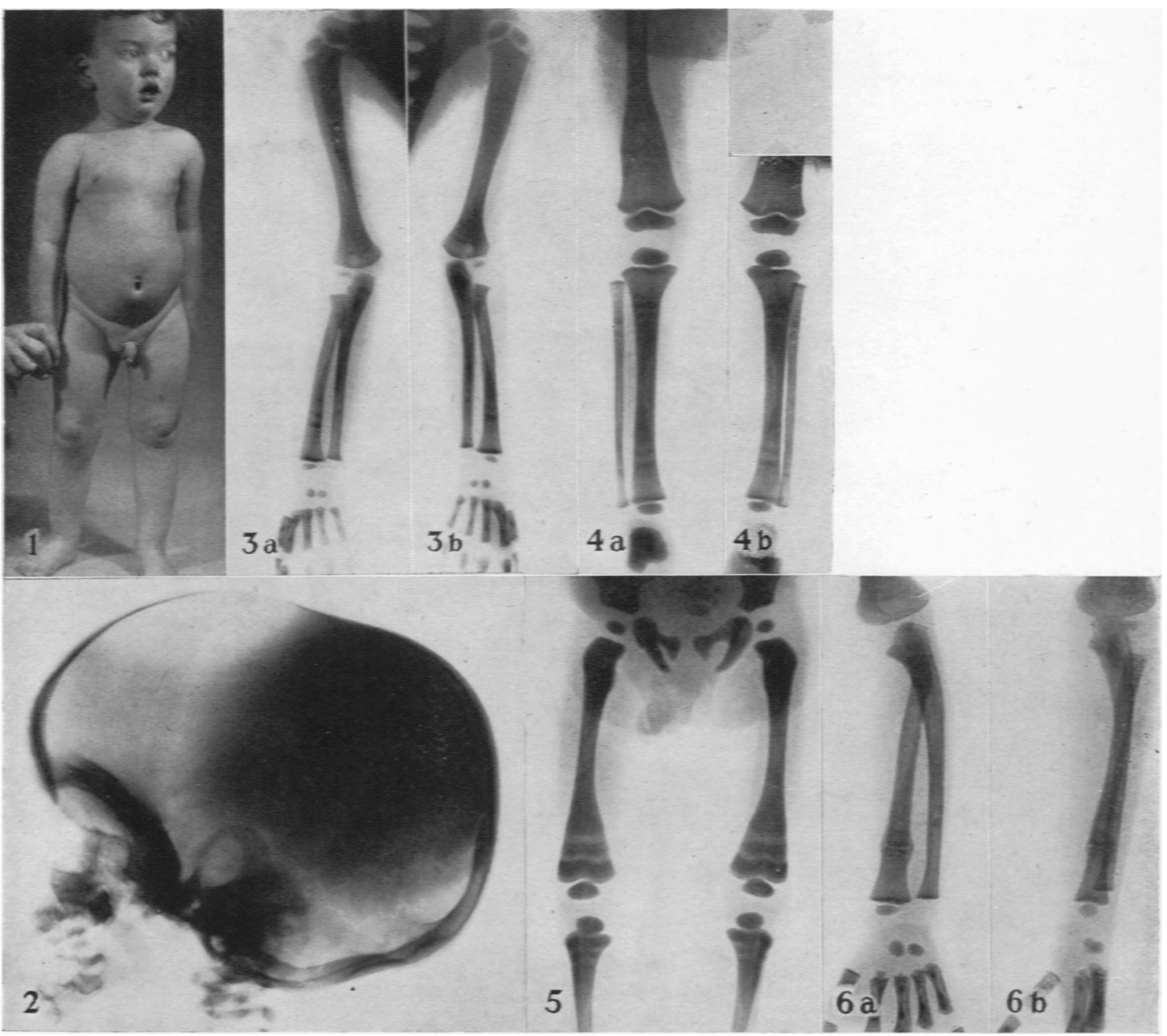

Fig. 1.-Case 1.-(Figs. 1 to 4 were all taken at 2 years and 2 months.)

FIG. 2.-Case 1. Note open anterior fontanelle.

Fig. 3.-Case 1, showing symmetrical distribution in upper limbs.

Fig. 4.- Case 1, showing symmetrical distribution and clubbing of lower end of femur. Note the remissions and their symmetry.

Fig. 5.-Case 1 at $9 \frac{1}{2}$ months, showing marked clubbing of the femora. Compare Fig. 4.

Fig. 6. - Case 1 at $2 \frac{1}{2}$ years, showing fracture of radius four weeks after its occurrence. 


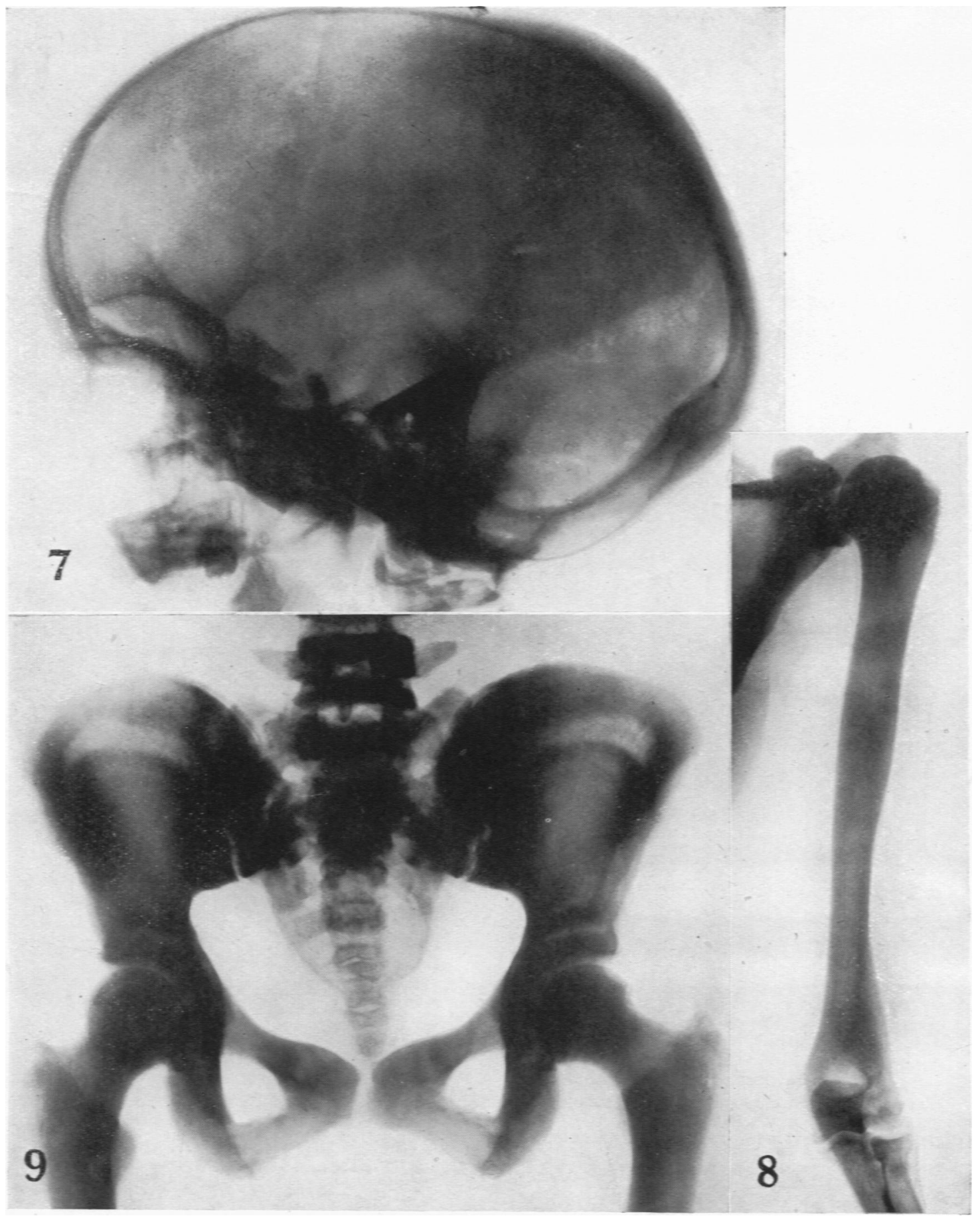

Fig. 7.-Case 2, aged 27 years, showing marked clubbing of the posterior clinoid process and well defined suture lines.

Fig. 8.- Case 2, showing abnormal modelling of the humerus.
Fig. 9.-Caše 2, showing symmetrical distribution in the pelvis. The patient has had two normal fullterm deliveries. 
despite the continuation of the parathyroid hormone injections. Selye (1932) noted that following upon the acquirement of resistance to experimental hyperparathyroidism, if the administration of parathyroid hormone were continued proliferation of osteoblasts occurred and a condition resembling osteopetrosis was produced. This osteoblastic reaction occurs at the same time as the experimentally induced hypercalcaemia and the increased calcium excretion return to normal (Pugsley and Selye, 1933). Ellis (1934) administered parathormone to two cases of osteopetrosis, and obtained a hypercalcaemia which reached its maximum in ten to nineteen days. This was followed by a rapid fall in the blood calcium, although the administration of parathormone was not stopped. This type of response to parathormone in cases of osteopetrosis might be explained by the patient being in a period of remission when the observations were made. The two cases now reported confirm that periods of remission do occur in this disease.

McPeak (1936) and Harnapp (1937) divide osteopetrosis into two groups: one of severe or malignant cases, and another of mild or benign cases. When this is done, it is seen that, so far as data are available in the recorded cases, parental consanguinity is frequent in the malignant group and infrequent in the mild group.

Nussey (1938) has shown that the frequency with which osteopetrosis is associated with parental consanguinity is much greater than the frequency of consanguineous marriages in the community. He suggests that the malignant group is an inherited recessive defect, and that the benign group is an inherited dominant defect. In accepting this grouping it should be kept in mind that in 60 per cent. of the recorded cases and in 66 per cent. of the families concerned it is not stated whether there was, or was not, a blood relationship between the parents.

In a great many instances there has been no radiological survey of the family. Pagenstecker (1935), for example, records the condition in a father and son. He obtained these two cases by chance, the father and son coming to him on different occasions for radiological examination. He did not investigate the family.

A survey of the literature shows that up to the present time eight instances of the occurrence of osteopetrosis in successive generations have been recorded. In arriving at this total the paper by Lauterburg (1926), quoted by Nussey (1938), has been excluded. Reference to this article shows that the two cases recorded were brothers, and not cases occurring in successive generations as stated by Nussey. The reference which Nussey should have given, but does not give, is Lauterburg (1931). The first record is by Ghormley (1922), who reported the condition in father and son; Lauterburg (1931) and Pagenstecher (1935) also reported it in father and son. Pirie (1930) recorded the condition in a mother and three of her children. The appearance of osteopetrosis in three successive generations is recorded by McPeak (1936). The cases were a woman, two of her daughters, and three granddaughters and two grandsons, all by one of these daughters. Zaleski (1932) records the condition in father and daughter. Harnapp (1937) noted an instance of the condition in a man, his two sons, and three of his five daughters. His two siblings were healthy and his parents healthy and unrelated. He was not related to his wife, who was seven months pregnant. Her unborn child was considered to be radiologically normal. Winter (1945) records osteopetrosis in an eighteen-year-old male and his fifty-five-year-old mother. In neither of these cases were the parents related.

Apart from Harnapp and Winter, none of these authors state whether or not there was parental consanguinity.

The cases reported by Pirie appear to have been of a benign type, though assessment is somewhat vitiated by a family history of diabetes for three generations. McPeak's cases are all considered to be benign, there being no blood dyscrasia, blindness, deafness, or mental defect, though fractures were present in some instances. The cases reported by Ghormley, Pagenstecher, Lauterburg, Zaleski, Harnapp and Winter all appear to be benign and showed no mental defect or optic atrophy.

While this is strong evidence in favour of a division into a malignant inherited recessive type and a benign inherited dominant type, it may be doubted whether the present cases can be so easily grouped. The mother of case 1 may be considered to show the condition in a benign form, but there is doubt about classifying the child as a benign case. Absence of blood dyscrasia and the tendency towards remission of the osteo-pathology shown by comparison of figs. 4 and 5 can be accepted as evidence of benignity. Against this must be set the presence of optic atrophy, mental defect, and the occurrence of fractures.

This is the first occasion on which optic atrophy and mental defect have been recorded in a case of osteopetrosis in the second generation, and it may be advisable to wait a year or two before finally classifying this case.

\section{Summary}

1. Osteopetrosis occurring in a mother and son is recorded.

2. The occurrence of fractures, optic atrophy, and mental defect in osteopetrosis in the second generation is recorded for the first time.

3. There are eight records of osteopetrosis in successive generations in addition to that now recorded.

4. The investigation of osteopetrosis should always include a statement of the family relationships and radiological examinations of parents and siblings if practicable. 


\section{REFERENCES}

Alter, N. M., Pease, M. C., and De Sanctis, A. G. (1931). Arch. Path., 11, 509.

Clifton, W. M., Frank, A., and Freeman, S. (1938). Amer. J. Dis. Child., 56, 1020.

Dupont, M. (1930). Thèse de Lyon. Quoted by Dijkstra, O. H. (1935). Ann. Anat. Path., 12, 131.

Ellis, R. W. B. (1934). Proc. R. Soc. Med., 27, 1563.

Ghormley, R. K. (1922). Bull. Johns Hopk. Hosp., 33, 444.

Harnapp, G. O. (1937). Mschr. Kinderheilk., 69, 1.

Higinbotham, N. L., and Alexander, S. F. (1941). Amer. J. Surg., 53, 444.

Jenkinson, E. L., Pfisterer, W. H., Latteier, K. K., and Martin, M. E. (1943). Amer. J. Roentgenol., 49, 455.

Kraus, E. J., and Walter, A. (1925). Med. Klin., 21, 19.
Lauterburg, W. (1926). Schweiz. med. Wschr., 56, 441. (1928). Ibid., 58, 677. (1931). Disch. Z. Chir., 230, 308.

Lorey, A., and Reye, -. (1923). Fortschr. Geb. Roentgenstrah., 30, 35.

McPeak, C. N. (1936). Amer. J. of Roentgenol., 36, 816. Nussey, A. M. (1938). Arch. Dis. Childh., 13, 161.

Pagenstecher, A. (1935). Röntgenfraxis, 7, 14.

Pirie, A. H. (1930). Amer. J. Roentgenol., 24, 147.

Pugsley, L. I. (1932). J. Physiol., 76, 315. , and Selye, H. (1933). Ibid., 79, 113.

Selye, H. (1932). Endocrinology, 16, 547. (1933). Jour. Am. Med. Assoc., 99, 108.

Vidgoff, B., and Bracher, G. J. (1940). Amer. J. Roentgenol., 44, 197.

Winter, G. R. (1945). Amer. J. Orthodont., 31, 637.

Zaleski, - (1932). Bull. Mem. Soc. Rad. Med. Paris, 20, 134. Quoted by Nussey and Harnapp. 